\title{
Comments on "Comparison of the influence of ozone and laser therapies on pain, swelling, and trismus following impacted third-molar surgery"
}

\author{
Wulin He $\cdot$ Fanyuan Yu $\cdot$ Peijia Duan
}

Received: 19 September 2013 / Accepted: 21 October 2013 /Published online: 30 November 2013

(C) Springer-Verlag London 2013

Dear Editor,

In the March 2013 issue of the online-first article, Kazancioglu et al. [1] reported that ozone and laser therapies are useful for the reduction of postoperative pain after third-molar surgery.

As we know, the perception of pain is such a subjective measurement that the result mainly depends on the patients' personal responses. Hence, excellent blinding of participants is required in order to reduce bias in outcome assessment [2]. Unfortunately, as far as I am concerned, this trial failed to include a control group using the pseudo-laser.

In the history of dentistry, the use of pseudo-laser in the field of low-level laser therapy after molar surgery has been described since the 1990s [3]. Within excellent study design, the handpiece in the placebo group has to be inserted intraorally or extraorally as in the laser group, but the laser is not activated, so that the participants are blinded as to which treatment they received $[4,5]$. However, Kazancioglu [1] simply used no treatment in the control group, which obviously undermined the reliability of pain assessment and increased detection bias as the participants are easily aware of which intervention they received.

Furthermore, individual variability in pain threshold and sensitivity is easily influenced by psychological factors. In addition, the operator's performance and indication, which are transferred subconsciously to the patients, would probably lead to a mistake that patients can distinguish between laser and ozone therapies. Thus, it also requires a good design in random

W. He $\cdot$ P. Duan $(\bowtie)$

Guangdong Provincial Stomatological Hospital, The Affiliated

Stomatological Hospital of Southern Medical University,

Guangzhou, Guangdong, China

e-mail: duanpeijia@sina.com

F. Yu

State Key Laboratory of Oral Diseases,

West China School of Stomatology, West China

Stomatological Hospital, Sichuan University,

Guangzhou, Guangdong, China sequence generation and allocation concealment to bring down the Hawthorne effect [6]. However, the author has not provided details about how the randomization was achieved. Although it stated that an independent surgeon performed the ozone therapy, he was not blind to this intervention. This may increase the performance and selection bias of this study [7].

Assessing scientific evidence from clinical trials is always a complex issue. Of course, this RCT can give us some information, but the problems in study design are non-ignorable. It demonstrated disadvantages in study design, allocation concealment, binding of participants, and outcome assessment. Those limitations reduced the reliability of its conclusion.

\section{References}

1. Kazancioglu HO, Ezirganli S, Demirtas N (2013) Comparison of the influence of ozone and laser therapies on pain, swelling, and trismus following impacted third-molar surgery. Lasers Med Sci. doi:10.1007/ s10103-013-1300-y

2. Higgins J, Altman D, Sterne J (2011) Assessing risk of bias in included studies. In: Higgins J, Green S (eds) Cochrane handbook for systematic reviews of interventions. Cochrane Collaboration, London

3. Carrillo JS, Calatayud J, Manso FJ (1990) A randomized double-blind clinical trial on the effectiveness of helium-neon laser in the prevention of pain, swelling and trismus after removal of impacted third molars. Int Dent J 40(1):31-36

4. Røynesdal AK, Björnland T, Barkvoll P, Haanaes HR (1993) The effect of soft-laser application on postoperative pain and swelling: a doubleblind, crossover study. Int J Oral Maxillofac Surg 22(4):242-245

5. Aras MH, Güngörmüș M (2010) Placebo-controlled randomized clinical trial of the effect two different low-level laser therapies (LLLT) intraoral and extraoral — on trismus and facial swelling following surgical extraction of the lower third molar. Lasers Med Sci 25(5):641-645

6. He WL, Li CJ, Liu ZP et al (2012) Efficacy of low-level laser therapy in the management of orthodontic pain: a systematic review and metaanalysis [J]. Lasers Med Sci Sep 22:1-9

7. Brignardello-Petersen R, Carrasco-Labra A, Araya I (2012) Is adjuvant laser therapy effective for preventing pain, swelling, and trismus after surgical removal of impacted mandibular third molars? A systematic review and meta-analysis. J Oral Maxillofac Surg 70(8):1789-1801 